\title{
A comparative evaluation of the retreatment efficiency of the Self-Adjusting File system and other root canal instrumentation techniques
}

\author{
Tuğrul Aslan, Burak Sağsen \\ Department of Endodontics, Erciyes University Faculty of Dentistry, Kayseri, Turkey
}

Objective: The aim of this study was to compare the retreatment efficiencies and durations of $\mathrm{H}$-file, Mtwo, Revo-S and SAF instruments.

Methods: 60 maxillary central incisors were used. Specimens were prepared by step-back technique and MAF was. 02/35 K-file. Root canals were irrigated, and dried; then, filled with gutta-percha and a sealer using cold lateral condensation technique. Canal filling removals were performed with. 02/35 $\mathrm{H}$-file and solvent. Specimens were randomly divided into 4 groups $(n=15)$. In final instrumentation: G1-.02/40 H file; G2-.06/40 Mtwo; G3-.06/40 Revo-S; G4- 2.0-mm SAF were used. Times required for retreatment were recorded. Final rinses were performed and root canals were dried with paper-points. Roots were split longitudinally and assessed by stereomicroscope at $6 \mathrm{X}$ magnification. Statistical analysis were done $(\alpha=0.05)$.

Results: There were no significant difference among root canal thirds and entire root canal surfaces of the groups $(p>0.05)$. There were significant difference among the groups in terms of required retreatment time $(p<0.05)$.

Conclusion: Although, SAF group was found as the slowest system among the tested groups, further retreatment studies on different the usage times of the SAF system, the usage combined with solvents and the usage in more challenging canal anatomies are needed.

Keywords: Nickel-titanium rotary file; retreatment; root canal; self-adjusting file.

$\mathrm{O}^{\mathrm{s}}$ rthograde retreatment may be considered when persistent pain or symptoms develop in a root canal treated tooth. Retreatment procedure involves the removal of the root canal filling, further cleaning, and refilling of root canal. ${ }^{[1]}$ Several instruments and solvents, heatbearing instruments and ultrasonics have been suggested for removing root canal materials. ${ }^{[2-4]}$ However, none of these retreatment methods achieves entirely clean root canal walls. ${ }^{[4]}$
Nickel-titanium $(\mathrm{Ni}-\mathrm{Ti})$ rotary instruments have been used for the removal of filling materials from root canal walls, and several studies reported their efficacy, cleaning ability and safety ${ }^{[4-6]}$ However, they also have some limitations and drawbacks. Some limitations of Ni-Ti rotary instruments are: complicated file systems, tedious irrigation, canal transportation, unexpected file separation, mismatch with three-dimensional shape of the root canal. ${ }^{[7]}$ The SelfAdjusting File (SAF) System was designed to overcome

Correspondence: Dr. Tuğrul Aslan. Erciyes Üniversitesi Diş Hekimliği Fakültesi,

Endodonti Anabilim Dalı, Melikgazi, 38039 Kayseri, Turkey.

Tel: +90 352 - 2076666 / 29137 e-mail: dr.tugrulaslan@hotmail.com

Submitted: February 09, 2016 Accepted: April 26, 2016

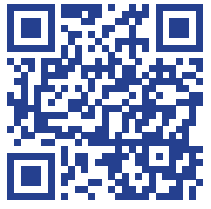


these drawbacks of the rotary file systems. SAF can adapt three-dimensionally to the shape of a root canal, including its cross section, by its highly compressible structure. [7] SAF works similar to a sandpaper on root canal walls, because the instrument has no cutting edges or flutes. ${ }^{[8]} \mathrm{It}$ is used with continuous irrigation delivered through the hollow file, using a special irrigation apparatus (VATEA irrigation device; ReDent Nova, Ra'anana, Israel). Previous $\mu \mathrm{CT}$ analysis remarked that SAF leaves a lower per cent of untouched root canal surfaces than the other preparation techniques. ${ }^{[9,10]}$

It could be reasonable that, SAF may also be effectively used as a second stage in a two-stage procedure for removing root filling material, as mentioned before by Abramovitz et al.. ${ }^{[1]]}$ There are few studies that compare the SAF System with other techniques in terms of retreatment procedure in the literature. Therefore, this study was designed to evaluate the root filling removal efficiencies of SAF the System and different instrumentation techniques at a two-stage retreatment procedure. The null hypothesis was that the instrumentation techniques did not differ in the removal of root filling material.

\section{Materials and methods}

\section{Teeth selection, preparation and obturation}

Sixty single and straight rooted human maxillary central incisor teeth with similar length were used. The criteria determined in the selection was the choice of the teeth which had an apical size of ISO 20 or less. To achive the standard length, the incisal edges were cut, so that the length of each specimen was $16 \mathrm{~mm}$. A size $10 \mathrm{~K}$-type hand file was placed into the canal until it was visible at the apical foramen. The working length was established 1 $\mathrm{mm}$ short of this length. Root canal preparation was performed by a step-back technique using 0.02 tapered hand files. Master apical file (MAF) was .02/35 K-type hand file for all canals. The canals were irrigated between each file with $3 \mathrm{ml}$ of $1 \% \mathrm{NaOCl}$ passively. Step-back preparation was finished with $\mathrm{H}$-type hand files up to three larger size of MAF instrument. A final irrigation with $5 \mathrm{ml}$ of $17 \%$ EDTA and $5 \mathrm{ml}$ of $1 \% \mathrm{NaOCl}$, and followed by $10 \mathrm{ml}$ of saline solution was used in all specimens. Then the root canals were dried with paper points and filled with guttapercha (Dentsply Maillefer, Petropolis, RJ, Brazil) and AH Plus (Dentsply DeTrey GmbH, Konstanz, Germany) root canal sealer by using cold lateral condensation technique. The coronal access cavities of the specimens were sealed with a temporary filling material (Zinc Oxide Eugenol Cement, Cavex Holland BV, Haarlem, Netherlands). To ensure the complete fillings of the specimens, periapical radigraphs were taken from different directions. The teeth were then stored at $37^{\circ} \mathrm{C}$ in $100 \%$ humidity for a month to allow the sealer to set.

\section{Retreatment procedure}

\section{First stage}

This study was performed in two stages. In the first stage, the temporary filling materials were removed, and to facilitate instrument penetration into the root canal, a drop of solvent Guttasolv (Septodont, Cedex, France) were applied on to the canal orifice. A $.02 / 35 \mathrm{H}$-type file was progressed into the canal, and when reached a new canal third, new solvent was added. The process was ended when the file reached working length (Fig. 1). Total use of solvent was $0.5 \mathrm{ml}$ during the process. The teeth were then randomly divided into 4 groups of 15 teeth each.

\section{Second stage}

In the second stage, the procedures were performed as below:

Group 1: The final preparation was performed with $.02 / 40 \mathrm{H}$-type hand file (Antaeos, VDW GmbH, Munich, Germany) with filing action.

Group 2: The final preparation was performed with .06/40 Mtwo instrument (VDW Dental, Munich, Germany).

Group 3: The final preparation was performed with .06/40 Revo-S instrument (Micro Mega, Besançon, France).

Group 4: The final preparation was performed with $2.0 \mathrm{~mm}$ SAF instrument (ReDent NOVA, Ra'anana, Israel) (Fig. 2) at 5000 vibrations per minute with an amplitude of $0.4 \mathrm{~mm}$ for 4 minutes. SAF instrument immediately reached the apex as the root filling was previously removed with hand files. No SAF instrument was broken.

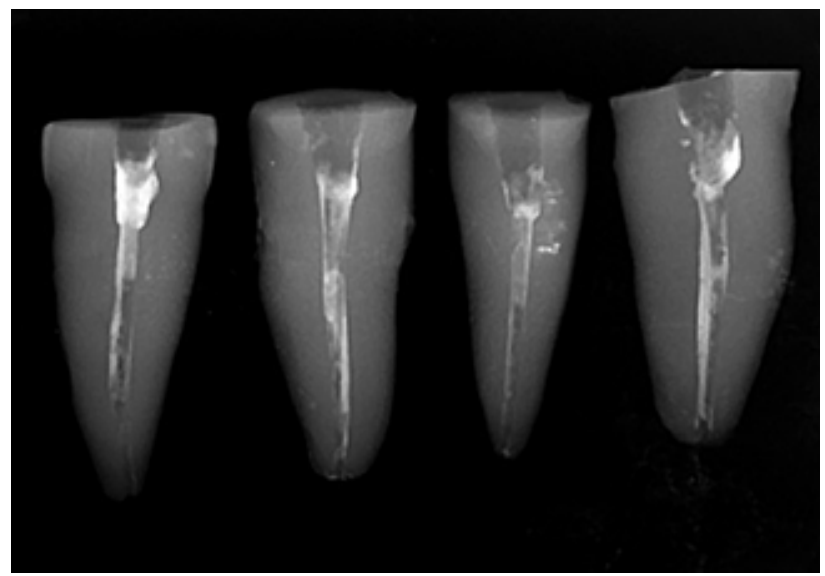

Fig. 1. Specimens after first stage of retreatment procedure by using $02 / 35 \mathrm{H}$-file. The process was ended when the file reached working length. 


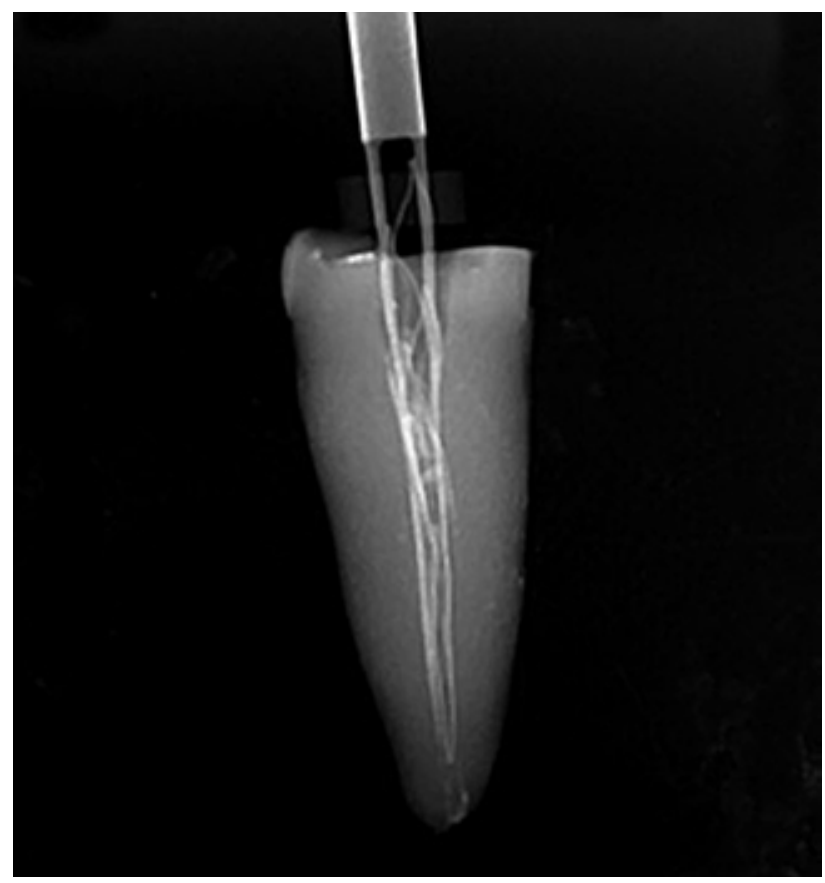

Fig. 2. Using SAF instrument in second stage of retreatment.

According to the manufacturer, only separation of some wires may occur in the SAF system. The continious irriga-

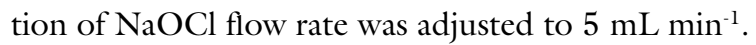

All rotary instruments were used with a torque and speed controlled electric motor (X Smart, Dentsply Maillefer, Ballaigues, Switzerland), according to the manufacturer's instructions The SAF file was operated with a RDT3 handpiece head (ReDent Nova, Ra'anana, Israel). The criteria for completion of retreatment were the presence of clean filings, no evident filling material on the files or paper points and smooth canal walls. For the final irrigation, $5 \mathrm{ml}$ of $17 \% \mathrm{EDTA}, 5 \mathrm{ml}$ of $1 \% \mathrm{NaOCl}$, followed by $10 \mathrm{ml}$ of saline solution was used, then the root canals were dried with paper points.

\section{Stereomicroscope evaluation and measurement}

The roots were grooved vertically with steel discs on the buccal and lingual surfaces. They were then split longitudinally with a chisel and a hammer into halves. The specimens were assessed under the stereomicroscope (SMZ745T, Nikon, Japan) at 6x magnification and images were taken from each half with a digital camera (Coolpix 5700, Nikon, Japan) which was attached to the microscope. Root canal thirds' outlines were determined by using Photoshop CS5 (Adobe Systems Inc., San Jose, USA). Images were transferred to Image J (Image J; National Institutes of Health, Bethesda, USA) software to evaluate the area of filling material remaining on the root canal walls in each portion (Fig. 3).

Remaining filling materials were calculated in percentages by dividing the area of remaining filling material by the total area of canal wall. The formula is indicated below:

$\%=$ Surface area of remaining filling material-Surface area of root canal third xl00

Also, the time was measured by means of a digital chronometer (Geonaute, Decathlon, China), in seconds (s), through the second stage procedure until achieving the cleaning criteria of the root canals.

\section{Statistical analysis}

The statistical interpretations were done with SPSS ver. 18.0 (SPSS Inc., Chicago, IL, USA) software. The data (percentages of remaining debris and time) were subjected to Shapiro-Wilk normality test for determination of distribution. The data were normally distributed; hence, OneWay ANOVA and Tamhane's T2 post-hoc tests were used to determine the statistically significant differences among the groups $(\alpha=0.05)$.

\section{Results}

\section{Comparisons of the root canal thirds and entire root canals among the groups}

There were no significant differences among the groups at apical, middle and coronal thirds of the root canals
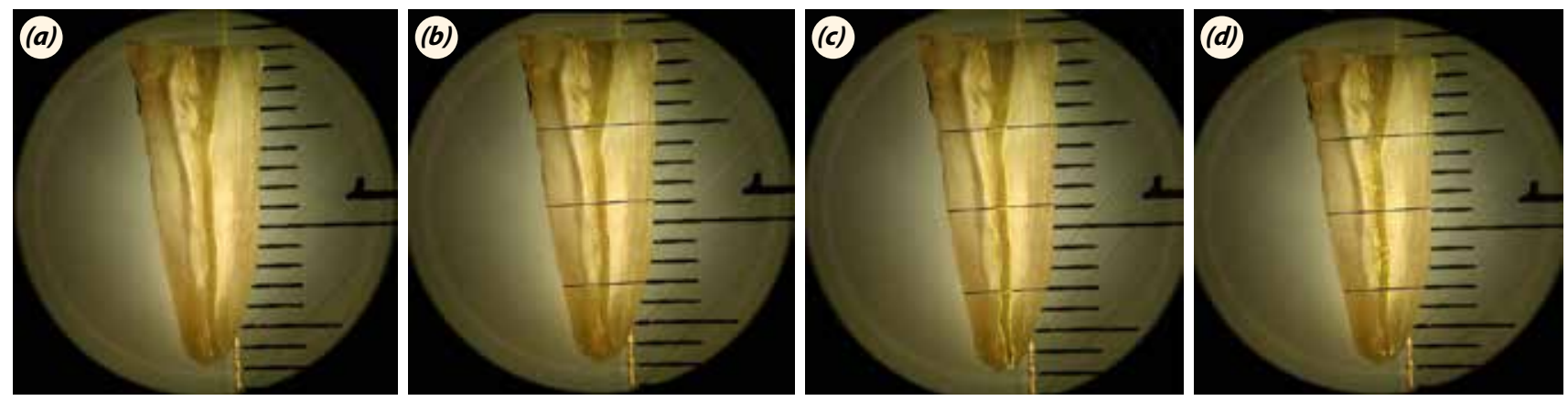

Fig. 3. (a) Photographs of the tooth halves were taken under stereomicroscope at $6 x$ magnification. (b) Root canal thirds' outlines were determined. (c) Each root canal thirds' surface areas were calculated. (d) Area of root canal filling residues on each root canal thirds were calculated. 
Table 1. Descriptive statistics of the groups at three root regions and entire root canal walls. Different superscripts indicate statistically significant differences

\begin{tabular}{|c|c|c|c|c|}
\hline & Mean (\%) & Standard deviation & Minimum & Maximum \\
\hline \multicolumn{5}{|l|}{ Apical } \\
\hline Hand file ${ }^{a}$ & 22.1393 & 18.88262 & 0.00 & 61.72 \\
\hline Mtwo $^{a}$ & 25.4787 & 16.71095 & 6.14 & 64.30 \\
\hline Revo-Sa & 27.4475 & 20.17114 & 5.20 & 56.99 \\
\hline Self-Adjusting File & 34.4679 & 21.40683 & 5.70 & 82.33 \\
\hline \multicolumn{5}{|l|}{ Middle } \\
\hline Hand file $^{b}$ & 34.8673 & 19.82351 & 0.00 & 69.03 \\
\hline Mtwo ${ }^{b}$ & 18.8580 & 17.30471 & 0.00 & 57.90 \\
\hline Revo-S ${ }^{b}$ & 22.6413 & 17.91195 & 0.00 & 61.49 \\
\hline Self-Adjusting File ${ }^{b}$ & 32.7080 & 26.61417 & 0.00 & 83.80 \\
\hline \multicolumn{5}{|l|}{ Coronal } \\
\hline Hand file ${ }^{c}$ & 36.2086 & 24.04019 & 5.56 & 78.62 \\
\hline Mtwo $^{c}$ & 27.8340 & 17.42538 & 1.15 & 58.05 \\
\hline Revo-Sc & 37.1867 & 23.35699 & 3.47 & 70.34 \\
\hline Self-Adjusting File ${ }^{c}$ & 25.5667 & 22.61655 & 0.00 & 72.86 \\
\hline \multicolumn{5}{|l|}{ Total } \\
\hline Hand file $^{d}$ & 34.8727 & 12.96749 & 5.49 & 60.00 \\
\hline Mtwo $^{d}$ & 25.3754 & 14.78286 & 6.57 & 52.20 \\
\hline Revo-S $S^{d}$ & 29.3600 & 15.84997 & 3.82 & 58.47 \\
\hline Self-Adjusting File ${ }^{d}$ & 31.6583 & 18.62813 & 4.64 & 63.96 \\
\hline
\end{tabular}

a-d: Letters were used as superscripts.

Table 2. Descriptive statistics of the cleaning time of the instrumentation techniques. Values are in second (s) unit. Different superscripts indicate statistically significant differences

\begin{tabular}{|c|c|c|c|c|}
\hline & Mean (\%) & Standard deviation & Minimum & Maximum \\
\hline Hand file $e^{e}$ & 174.2000 & 67.08651 & 87 & 318 \\
\hline Mtwof & 54.8000 & 13.55518 & 32 & 84 \\
\hline Revo-Sg & 103.6000 & 19.76577 & 63 & 130 \\
\hline Self-Adjusting File ${ }^{h}$ & 240.0000 & 0.00000 & 240 & 240 \\
\hline
\end{tabular}

$\mathrm{e}-\mathrm{h}$ : Letters were used as superscripts.

( $p>0.05)$. Means, standard deviations and minimum-maximum values are shown in Table 1.

\section{Comparisons of the residual gutta-percha removal time among the groups}

There was a statistically significant difference among the groups $(\mathrm{p}<0.05)$. Means, standard deviations and minimum-maximum values are shown in Table 2 . According to the results, Mtwo was the fastest system; and followed by Revo-S system. These systems was followed by the hand file group; and the slowest group was the SAF system.

\section{Discussion}

$\mathrm{Ni}$-Ti rotary instruments differ from each other by their designs. The differences in the designs can be listed as dif- ferent taper, cutting edge, grooves and tip designs; and these might influence the efficiency of Ni-Ti rotary instruments. ${ }^{[4,12]}$ However, the SAF system's design is different from rotary files. The SAF instrument is designed as a hollow cylinder constructed from a thin $\mathrm{Ni}$-Ti lattice that can take the form of the canal. Besides, it has a tip which has an asymmetrical taper. ${ }^{[7]}$ The SAF system which is operated with a vertical vibration (in and out) motion and in which there is a system containing a continuous fresh irrigation solution at the same time, ${ }^{[13]}$ is reported to be able to contact up to the $92 \%$ of the canal wall during the preparation. ${ }^{[14]}$ One important disadvantage of the $\mathrm{Ni}-\mathrm{Ti}$ rotary systems compared to the SAF system is that they can not contact more than $60 \%$ of the surface of the root canal walls during the preparation because their cross sections are round. ${ }^{[15]}$ 
For a better cleaning during the retreatment, the canal should be enlarged more than the initial treatment. ${ }^{[2]}$ Due to this reason, an instrument (40 size), which is one size bigger than the first preparation width, was chosen as the final instrument. Also, .06 taper rotary instruments were preferred in this study because of its big taper for better removal of the canal filling. In this study, the Ni-Ti rotary systems (frequently preferred in clinics) were used.

Usage of solvents in the removal of root canal filling material has a time-saving and facilitating effect for the removal. ${ }^{[16]}$ In this study, eucalyptol which is a reliable and effective solvent due to its clinically common usage and its positive effects seen in the different studies ${ }^{[17]}$ is preferred in the first stage of the retreatment.

The role of the irrigation has a very crucial importance in obtaining satisfactory debridement and asepsis in the root canal treatment, in that it can remove the organic materials, microorganisms and toxins. ${ }^{[18]}$ The more apical enlargement the canals has, the larger scale of the irrigation penetration to the apical thirds is performed. ${ }^{[19]}$ In this context, it can be said that cleaning activity after the preparation is successful in our study. In the SAF group, besides the effect of sanding action of the SAF instrument, continuous fresh flow of $\mathrm{NaOCI}$ solution and the ongoing agitation improve the effectivity of cleaning, especially in difficult areas like apical third of root canal.[20]

The canal filling material remaining in the previous retreatment studies was analysed by a variety of method such as: radiographical assessment, examination of the residual filling material under the microscope after longitudinal bisection of roots and assessing with the computer software, micro CT scan, rendering the roots transparent and carrying out the computer-aided measurements. ${ }^{[5,16,21,22]}$ The methods preferred in this study are the methods of examining the residual filling material under the microscope after longitudinal bisection of roots, and the method of assessing with computer software. Due to its practical applicability and low cost and because it is still used in the studies carried out, ${ }^{[4,12]}$ this method was preferred. The method of longitudinal bisection of roots also provides the opportunity for three dimensional examination according to the radiography.

The SAF system presents a new design and operation concept in endodontic files. ${ }^{[8,13]}$ It is asserted that SAF instrument is firmly adapted to even oval and flat-oval root canals. ${ }^{[9,13]}$ It is used with a special micromotor head which can produce 5000 in minute up and down and $0.4 \mathrm{~mm}$ in width oscillation. It is operated with a pecking motion. In one study, it is reported that apical diameter after a preparation with SAF instrument reached at least number 40 file equivalent. ${ }^{[23]}$ The manufacturer of the SAF sys- tem designed the $2.0 \mathrm{~mm}$ sized instrument to be used in wide canals with an apical diameter between ISO 35-60, in retreatment, on upper central incisors, canines and the young patient group (http://www.redent.co.il//userfiles/file/flipbook/index.html). Therefore, in this study, SAF instruments $2.0 \mathrm{~mm}$ in diameter were preferred.

It has been reported that the SAF system uniformly removes a dentine layer from the whole canal section. ${ }^{[24]}$ Another study reported that SAF system removes dentine debris effectively even in apical areas of oval canals. ${ }^{[25]}$ In previous studies, the SAF system was found superior to the traditional $\mathrm{Ni}$-Ti rotary systems in its ability to prepare oval shaped canals, in pulp tissue debridement, the cleaning of hard tissue debris, in increasing obturation quality, and in removing residual gutta percha after retreatment. [11,26-29] The SAF instrument cannot be accepted as an instrument that can remove root canal filling material mass because it has an extremely flexible structure and design that cannot penetrate into a mass. ${ }^{[1]}$ So, the main mass of the canal filling material needs to be removed with another instrumentation system. Thus, the hypothesis that it can be used effectively as a second step procedure is asserted. ${ }^{[11]}$ In this study, the SAF instruments were used in second step.

In a study, Abramovitz et al. removed root canal filling as the first step in a treatment process using ProTaper retreatment files combined with chloroform. At the end of first step, they radiographically evaluated the roots in terms of residual canal filling and determined the residue amount. In the second step, they used the SAF system to remove the canal residue in the canal. At the end of their studies, they reported that using the SAF system in the second step significantly decreases the residual canal filling amount. ${ }^{[1]]}$ This study is important in presenting the effectiveness of using the SAF system in the second step. Voet et al., in their study on oval and curved root canals, found out that when the SAF system is used additionally, residual root filling amount decreases. ${ }^{[30]}$ This study shows that using the SAF system additionally is effective in the presence of difficult canal anatomies. Keleş et al., in their study in which they evaluated the usage of additional SAF system in retreatment on oval root canals, showed that using SAF system as the second step has positive effects in removing root canal filling material. ${ }^{[31]}$ Solomonov et al. investigated the effectiveness of the SAF system using oval root canals. They removed root canal filling material with ProTaper Universal Retreatment D1, D2 and D3 intruments in a group and then they used F1 and F2 instruments. In the other group they removed the root canal filling material with $.06 / 25$ ProFile instrument and then they used the SAF instrument $2.0 \mathrm{~mm}$ in diameter. ${ }^{[32]}$ According to the 
results of the study, ProFile+SAF group obtained cleaner canals.

In the present study, all retreatment techniques left filling material residue on canal walls. This result is in accordance with the findings of other studies in which different retreatment instruments, techniques and solvents were used. ${ }^{[4,6,33]}$ In this study, in the analysis of root thirds and all root surface area, a statistically significant difference between the SAF system and other instrumentation methods couldn't be found ( $>0.05$ ). This might originate from the flat root anatomies of the teeth and the use of high conical Ni-Ti rotary files. The usage of SAF system with ongoing irrigation process ensures the reduction of debris in root canal system significantly. ${ }^{[34]}$ According to the findings of this study, this feature of the SAF system did not provide an extra advantage in flat and round root canals. However, due to the limitations of this study, how irrigation will affect this results cannot be deduced.

In our study, when analysed under microscope, guttapercha and root canal sealer were seen intensively on canal walls in some samples, but only sealer was seen fragmentary in other samples. However, as the surface area of the residue was taken into account, if equal amount of canal surface was occupied in total in two cases they were reflected as equal to the results. The limitation of this study was that the results did not give the amount of mass of canal filling residue, but merely the surface area they occupy. For further studies, it is more convenient to measure the weights with precision scales.

In this study, the two-step step procedure is applied to the groups. In the first step of this dual procedure, it was aimed to remove the root canal filling material in the working length in the first step; and to clean the residue on canal walls in the second. Due to the standard process applied in the first step, time measurements were performed in the second step. The aim was to make statistical comparison between the canal filling residue removal times of the instrumentation systems used.

Mtwo system's producing the shortest time can be attributed to its aggressive design that has two cutting sides with a positive cutting angle; and this might result in a significant difference with regard to the other $\mathrm{Ni}$-Ti rotary file groups. Revo-S showed the second fastest cleaning times, and this may be the result of its asymmetric and aggressive cutting design. Imura et al. found Hedström hand files faster than Quantec Ni-Ti rotary system; and they argued that Hedström files removed bigger Gutta percha parts. ${ }^{[5]}$ Moreover, in our study, hand files took more time than $\mathrm{Ni}-\mathrm{Ti}$ rotary files; this is in accordance with many previous studies. ${ }^{[3,16,33]}$

The reason the SAF system takes the longest time is that it was used for 4 minutes ( $240 \mathrm{sec}$.), in accordance with the manufacturer's suggestion. Further studies are needed to research the root canal filling residue removal time of the SAF system since in the present study canal filling residue might have removed before 4 minutes.

\section{Conclusions}

When the effectiveness of cleaning canal filling residue was examined, no difference was found between SAF, Mtwo, Revo-S and H-type hand files. In terms of residual material removal time, Mtwo was the fastest system; and followed by Revo-S system. These systems was followed by the hand file group; and the slowest group was the SAF system. Further retreatment studies on different the usage times of the SAF system, the usage combined with solvents and the usage in more challenging canal anatomies are needed.

\section{Acknowledgements}

This study was supported by the Erciyes University Scientific Research Projects Unit (TSD-11-3722).

Conflict of interest: None declared.

\section{References}

1. Stabholz A, Friedman S. Endodontic retreatment--case selection and technique. Part 2: Treatment planning for retreatment. J Endod 1988;14:607-14. Crossref

2. Friedman S, Moshonov J, Trope M. Efficacy of removing glass ionomer cement, zinc oxide eugenol, and epoxy resin sealers from retreated root canals. Oral Surg Oral Med Oral Pathol 1992;73:609-12. Crossref

3. Betti LV, Bramante CM. Quantec SC rotary instruments versus hand files for gutta-percha removal in root canal retreatment. Int Endod J 2001;34:514-9. Crossef

4. Kosti E, Lambrianidis T, Economides N, Neofitou C. Ex vivo study of the efficacy of $\mathrm{H}$-files and rotary $\mathrm{Ni}$ - $\mathrm{Ti}$ instruments to remove gutta-percha and four types of sealer. Int Endod J 2006;39:48-54. Crossref

5. Imura N, Kato AS, Hata GI, Uemura M, Toda T, Weine F. A comparison of the relative efficacies of four hand and rotary instrumentation techniques during endodontic retreatment. Int Endod J 2000;33:361-6. Crossref

6. Saad AY, Al-Hadlaq SM, Al-Katheeri NH. Efficacy of two rotary $\mathrm{NiTi}$ instruments in the removal of Gutta-Percha during root canal retreatment. J Endod 2007;33:38-41.

7. Metzger Z. From files to SAF: $3 D$ endodontic treatment is possible at last. Alpha Omegan. 2011;104:36-44.

8. Hof R, Perevalov V, Eltanani M, Zary R, Metzger Z. The self-adjusting file (SAF). Part 2: mechanical analysis. J Endod 2010;36:691-6. Crossref 
9. Paqué F, Peters OA. Micro-computed tomography evaluation of the preparation of long oval root canals in mandibular molars with the self-adjusting file. J Endod 2011;37:517-21. Crossref

10. Peters OA, Paqué F. Root canal preparation of maxillary molars with the self-adjusting file: a micro-computed tomography study. J Endod 2011;37:53-7. Crossref

11. Abramovitz I, Relles-Bonar S, Baransi B, Kfir A. The effectiveness of a self-adjusting file to remove residual gutta-percha after retreatment with rotary files. Int Endod J 2012;45:386-92. Crossref

12. Fenoul G, Meless GD, Pérez F. The efficacy of R-Endo rotary $\mathrm{NiTi}$ and stainless-steel hand instruments to remove gutta-percha and Resilon. Int Endod J 2010;43:135-41.

13. Metzger Z, Teperovich E, Zary R, Cohen R, Hof R. The self-adjusting file (SAF). Part 1: respecting the root canal anatomy--a new concept of endodontic files and its implementation. J Endod 2010;36:679-90. Crossref

14. Peters OA, Boessler C, Paqué F. Root canal preparation with a novel nickel-titanium instrument evaluated with micro-computed tomography: canal surface preparation over time. J Endod 2010;36:1068-72. Crossref

15. Paqué F, Balmer M, Attin T, Peters OA. Preparation of oval-shaped root canals in mandibular molars using nickeltitanium rotary instruments: a micro-computed tomography study. J Endod 2010;36:703-7. Crossref

16. Ferreira JJ, Rhodes JS, Ford TR. The efficacy of gutta-percha removal using ProFiles. Int Endod J 2001;34:267-74.

17. Hunter KR, Doblecki W, Pelleu GB Jr. Halothane and eucalyptol as alternatives to chloroform for softening guttapercha. J Endod 1991;17:310-1. Crossref

18. Siqueira JF Jr, Rôças IN, Santos SR, Lima KC, Magalhães FA, de Uzeda M. Efficacy of instrumentation techniques and irrigation regimens in reducing the bacterial population within root canals. J Endod 2002;28:181-4. Crossref

19. Salzgeber RM, Brilliant JD. An in vivo evaluation of the penetration of an irrigating solution in root canals. J Endod 1977;3:394-8. Crossref

20. De-Deus G, Accorsi-Mendonça T, de Carvalho e Silva L, Leite CA, da Silva D, Moreira EJ. Self-adjusting file cleaning-shaping-irrigation system improves root-filling bond strength. J Endod 2013;39:254-7. Crossref

21. Marfisi K, Mercade M, Plotino G, Duran-Sindreu F, Bueno R, Roig M. Efficacy of three different rotary files to remove gutta-percha and Resilon from root canals. Int Endod J 2010;43:1022-8, Crossref

22. Akpinar KE, Altunbaş D, Kuştarcı A. The efficacy of two rotary $\mathrm{NiTi}$ instruments and $\mathrm{H}$-files to remove gutta- percha from root canals. Med Oral Patol Oral Cir Bucal 2012; 17:506-11. Crossref

23. Metzger Z, Zary R, Cohen R, Teperovich E, Paqué F. The quality of root canal preparation and root canal obturation in canals treated with rotary versus self-adjusting files: a three-dimensional micro-computed tomographic study. J Endod 2010;36:1569-73. Crossref

24. Siqueira JF Jr, Alves FR, Almeida BM, de Oliveira JC, Rôças IN. Ability of chemomechanical preparation with either rotary instruments or self-adjusting file to disinfect oval-shaped root canals. J Endod 2010;36:1860-5. Crossref

25. de Melo Ribeiro MV, Silva-Sousa YT, Versiani MA, Lamira A, Steier L, Pécora JD, et al. Comparison of the cleaning efficacy of self-adjusting file and rotary systems in the apical third of oval-shaped canals. J Endod 2013;39:398-401.

26. Paranjpe A, de Gregorio C, Gonzalez AM, Gomez A, Silva Herzog D, Piña AA, et al. Efficacy of the self-adjusting file system on cleaning and shaping oval canals: a microbiological and microscopic evaluation. J Endod 2012;38:226-31.

27. De-Deus G, Souza EM, Barino B, Maia J, Zamolyi RQ, Reis $C$, et al. The self-adjusting file optimizes debridement quality in oval-shaped root canals. J Endod 2011;37:7015. Crossref

28. Paqué F, Laib A, Gautschi H, Zehnder M. Hard-tissue debris accumulation analysis by high-resolution computed tomography scans. J Endod 2009;35:1044-7. Crossref

29. De-Deus G, Barino B, Marins J, Magalhães K, Thuanne E, Kfir A. Self-adjusting file cleaning-shaping-irrigation system optimizes the filling of oval-shaped canals with thermoplasticized gutta-percha. J Endod 2012;38:846-9.

30. Voet KC, Wu MK, Wesselink PR, Shemesh H. Removal of gutta-percha from root canals using the self-adjusting file. J Endod 2012;38:1004-6. Crossref

31. Keleş A, Alcin H, Kamalak A, Versiani MA. Oval-shaped canal retreatment with self-adjusting file: a micro-computed tomography study. Clin Oral Investig 2014;18:114753. Crossref

32. Solomonov M, Paqué F, Kaya S, Adigüzel O, Kfir A, Yiğit-Özer S. Self-adjusting files in retreatment: a highresolution micro-computed tomography study. J Endod 2012;38:1283-7. Crossref

33. Hülsmann M, Bluhm V. Efficacy, cleaning ability and safety of different rotary $\mathrm{NiTi}$ instruments in root canal retreatment. Int Endod J 2004;37:468-76. Crossref

34. Metzger Z, Teperovich E, Cohen R, Zary R, Paqué F, Hülsmann $M$. The self-adjusting file (SAF). Part 3: removal of debris and smear layer-A scanning electron microscope study. J Endod 2010;36:697-702. Crossref 